Methods: RMD patients treated with COMBO therapy where enrolled from a single centre rheumatology unit; for each case, at least one MONO therapy control (matched per age \pm 5 years, sex, bDMARD, RMD, without osteoporosis) was enrolled. Data on clinical efficacy (3-points Likert scale for physician and patient - improved/stable/worse), safety (locl reaction, serious and non-serious adverse events) and bDMARD treatment retention at 12,18 and 24 months.

Results: Out of 129 eligible patients, 77 were enrolled in the protocol: 49 in the MONO and 28 in the COMBO group. The two groups were different of age (slightly higher in the COMBO group), for tender joint count, erythrocyte sedimentation rate and c-reactive protein (higher in the MONO group). Efficacy analysis showed higher percentage of clinical improvement at 12 months in the MONO group at 12 months, being not significant at 18 and 24 months (possibly explained by a different disease activity at baseline visit, corresponding to the overlap of denosumab on top of bDMARD in the COMBO and to the initiation of bDMARD in the MONO group). Between the 2 groups, no difference about safety and retention rate was found.

Conclusion: the efficacy of COMBO treatment is similar to MONO therapy. Moreover, the data show that also safety and retention rate are similar. Therefore, the COMBO treatment with 2 different monoclonals can be safely employed in the treatment of RMDs and osteoporosis.

Disclosure of Interests: Cosimo Bruni: None declared, Cosimo Cigolini: None declared, Giulia Tesei: None declared, Francesca Bartoli: None declared, Ginevra Fiori: None declared, Maria Letizia Conforti: None declared, Silvia Bellando Randone: None declared, Serena Guiducci: None declared, Marco Matucci-Cerinic Grant/research support from: Actelion, MSD, Pfizer, BMS, Chemomab, Sanipedia, Speakers bureau: Actelion, BMS; MSD, Janssen

DOI: 10.1136/annrheumdis-2019-eular.3505

\section{AB0370 EFFICACY AND SAFETY OF BIOLOGIC TREATMENT IN ELDERLY RHEUMATOID ARTHRITISPATIENTS: A WIDE COHORT STUDY}

Cristian Caimmi, Federica Martinis, Ilaria Montanari, Alice Dellaidotti,

Elena Fracassi, Ombretta Viapiana, Domenico Biasi, Maurizio Rossini,

Antonio Carletto. Rheumatology Unit, University of Verona, Verona, Italy

Background: Given the data on efficacy and safety of biologic treatment in rheumatoid arthritis (RA), more and more patients older than 65 years are starting these drugs.

Objectives: This study aims to evaluate safety and efficacy of biologics in elderly patients.

Methods: four-hundred and thirteen patients with RA were enrolled and divided in two group, i.e. older or younger than 65 years old. Data on disease characteristics, treatment and adverse reactions were collected. In addition, comorbidities were evaluated by the Rheumatic Disease Comorbidity index (RDCl).

Results: Seventy-seven patients were male and 87 were older than 65 years. The elderly patients had a higher $\mathrm{RDCl}$ as compared to those younger than 65 years $(1.0 \pm 3.0$ vs. $0.0 \pm 10$ respectively, $p<0.001)$. Mean DAS28 at the beginning of biologic treatment was $4.46 \pm 1.16$. Most of patients started etanercept $(41.4 \%)$ or adalimumab $(26.9 \%)$ and $37.1 \%$ were on monotherapy. None of these variables were statistically different between age groups. The figure shows the differences in retention rate of first biologic at 60 months in the two groups that was found to be significantly higher in older than younger patients (43.3 vs. 48.5 , $\mathrm{p}=0.023$ ). This result was confirmed also after correcting for comorbidities as defined by $\operatorname{RDCl}(p=0.014)$. On the contrary, no differences were found in retention rate on any biologic (i.e. not only first line) between age groups $(p=0.509)$. The main reason for biologic treatment discontinuation was inefficacy in both groups $(74.7 \%$ in $<65$ years old and $58.6 \%$ in $\geq 65$ years old, $\mathrm{p}=0.161$ ). The most common side effects in elderly patients were hematological complications (30.4\%) while in younger patients muco-cutaneous $(32.4 \%)$ adverse reactions. Infections were a reason for discontinuation in $17.4 \%$ in old patients and $20.6 \%$ in younger ones $(p=1.000)$.

Conclusion: RA patients aged over 65 years have been found to have even a better retention rate at first biologic than youngers one, probably because of less strict targets in disease control and a more frequent follow up. In addition, safety has been found to be as good as in younger patients. Comorbidities do not seem to affect retention rate.
Figure. Retention rate in patients $<65$ years old (blue line) vs patients $\geq 65$ years old (green line) $(\mathrm{p}=0.023$ ).

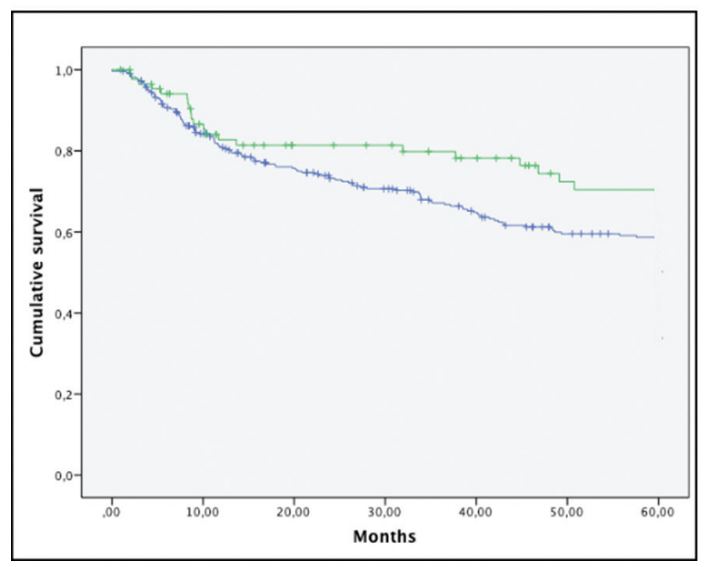

Figure 1

Disclosure of Interests: Cristian Caimmi: None declared, Federica Martinis: None declared, Ilaria Montanari: None declared, Alice Dellaidotti: None declared, Elena Fracassi Speakers bureau: Novartis, Ombretta Viapiana Speakers bureau: Novartis, Abbvie, Eli-Lilly, Sanofi Genzyme, Domenico Biasi: None declared, Maurizio Rossini: None declared, Antonio Carletto Speakers bureau: Roche, Novartis, MSD, Abbvie, Bristol, Jannsen, Celgene, Pfizer

DOI: 10.1136/annrheumdis-2019-eular.5367

\section{AB0371 LONG TERM RITUXIMAB PERSISTENCE FOR RHEUMATOID ARTHRITIS IN THE REAL WORLD: THE RITAR STUDY}

Iciar Cañamares Orbis ${ }^{1,2}$, Leticia Merino-Meléndez ${ }^{3}$, Irene Llorente ${ }^{4}$, Juana Benedi Gonzalez ${ }^{5}$, Rosario Garcia de Vicuna ${ }^{4}$, Alberto Morell ${ }^{1}$, Isidoro GonzálezÁlvaro ${ }^{4}$, Esther Ramirez ${ }^{2}$. ${ }^{1}$ Servicio Madrileño de Salud, Direction of Pharmaceutical Management, Madrid, Spain; ${ }^{2}$ Hospital Universitario La Princesa, Pharmacy, Madrid, Spain; ${ }^{3}$ Hospital San Pedro, Rheumatology, Logroño, Spain; ${ }^{4}$ Hospital Universitario La Princesa, IIS-IP, Rheumathology, Madrid, Spain; ${ }^{5}$ Universidad Complutense de Madrid, Pharmacology, Pharmacognosy and Botany, Madrid, Spain

Background: Rituximab (RTX) is a B-lymphocyte depleting monoclonal antibody that was approved for rheumatoid arthritis (RA) treatment in Europe in 2006.

Objectives: To analyse factors affecting long term persistence of RTX for the treatment of RA patients in daily clinical practice.

Methods: RITAR (RITuximab en Artritis Reumatoide) is a retrospective, open-label, observational study that describes the patterns of use and long term persistence of RTX in a tertiary university hospital from 2003 to 2015. We collected demographic, clinical and therapeutic variables. Patients who discontinued RTX were considered events whereas patients lost for follow-up and non-RTX-related deaths were censored. Statistical analysis was performed with STATA 12. Kaplan-Meier survival analysis, Log-rank test and Cox Regression were used. A multivariable Cox-proportional hazards model was fitted to determine which variables were most likely related to RTX persistence.

Results: 114 patients were included: $80.7 \%$ women, median age 60 years (IQR 51-69) and median RA duration 11 years (IQR 6-16). Most patients were FR/ACPA positive $(93.0 \%)$. Retreatment schedule was $94.6 \%$ on demand and $5.4 \%$ fixed-retreatment every 6 months. In the $1^{\text {st }}$ cycle RTX monotherapy used in $12.2 \%$ and gradually increased over time. The mean RTX dose by cycle was 1,733 mg (DE: 294): 324 × $2000 \mathrm{mg}$ and $130 \times 1000 \mathrm{mg}$. RTX was used as $1^{\text {st }}$ biologic in $19.3 \%$. Median response duration was 10 months (IQR 7-13).

We observed 38 events, 22 patients were censored and 54 remained on RTX treatment at the end of the study. Follow-up time in analysis was 484.84 years. Median survival was 9.98 years, withdrawal rate was 7.67 100 patients-year. Reasons for discontinuation were $21.0 \%$ ineffectiveness, $8.7 \%$ adverse events and $3.5 \%$ deaths probably related with RTX. 